\title{
Pasture-associated Liver Disease in Horses ${ }^{1}$
}

\author{
A.M. House and J.R. Elfenbein ${ }^{2}$
}

Diseases of the equine liver can be a challenge to diagnose and treat. The clinical signs of liver disease in horses are often non-specific and may include poor appetite, weight loss, icterus (yellow color of the gums and eyes), fever, mild colic, and others. The most common causes of pastureassociated liver disease are the pyrrolizidine alkaloid plants, panicum grasses, and clover (alsike and red clover). Veterinarians can perform diagnostic testing, which can be a valuable tool for determining the underlying cause and prognosis of liver disease and directing appropriate therapy.

\section{Introduction}

The liver regulates energy metabolism and eliminates foreign substances from the body. Horses with liver disease may not initially have any clinical signs at all, or the symptoms can be very vague. Common historical and physical examination abnormalities include icterus, poor body condition, anorexia, lethargy, and intermittent mild colic. Some horses develop "sunburned" crusty, painful skin lesions (especially in white areas) due to photosensitization. Neurologic abnormalities are typically associated with advanced liver disease, and these can range from subtle behavioral changes to head pressing and coma. Other signs of liver disease include diarrhea, swelling along the ventral abdomen, excessive drinking, bilateral laryngeal paralysis (which will cause difficulty breathing and a "roaring" noise), and injected (excessively red or congested) mucous membranes. Liver disease is often severe and widespread prior to diagnosis because clinical signs won't appear until a horse loses more than $80 \%$ of its liver function. ${ }^{1}$

\section{Causes of Pasture-associated Liver Disease}

Chronic megalocytic hepatopathy is the most common cause of chronic liver disease in horses in the United States. ${ }^{2}$ It is caused by ingestion of plants that contain pyrrolizidine alkaloid (PA), including Crotalaria spp, Senecio spp, Amsinckia spp, Heliotropium europaeum, Echium plantagineum, and Cynoglossum officinale. ${ }^{3-8}$ Toxicity is cumulative over the course of a horse's lifetime, and the consumption of $2 \%-5 \%$ of a horse's body weight is required for induction of liver disease. ${ }^{3}$ These plants are generally unpalatable to horses, but palatability increases with weather extremes such as drought or frost. The alkaloid remains toxic despite drying, so horses may become intoxicated by exposure to plants baled into hay. In addition, pastures may become overgrown with the toxic plant, which increases the likelihood of consumption. Toxicity occurs in horses of all ages and breeds, but not all horses on a farm will develop signs of hepatic dysfunction. ${ }^{9}$

Clinical signs of PA toxicity typically develop weeks to months following consumption of a sufficient quantity of the toxic plant and are consistent with chronic hepatic disease. ${ }^{3,5}$ Blood samples can be evaluated for increases in liver specific enzymes. Lab work abnormalities at the time of diagnosis include but are not limited to increases

1. This document is VM180, one of a series of the College of Veterinary Medicine-Large Animal Clinical Sciences Department, Florida Cooperative Extension Service, Institute of Food and Agricultural Sciences, University of Florida. Original publication date August 2011. Visit the EDIS website at http://edis.ifas.ufl.edu.

2. A.M. House, DVM, DACVIM, assistant professor, College of Veterinary Medicine -- Large Animal Clinical Sciences Department, and J.R. Elfenbein, DVM, DACVIM, resident in large animal medicine, College of Veterinary Medicine -- Large Animal Clinical Sciences Department; Florida Cooperative Extension Service, Institute of Food and Agricultural Sciences, University of Florida, Gainesville, FL 32611. 
in $\gamma$-glutamyl transferase (GGT), alkaline phosphatase (ALP), and serum bile acids. ${ }^{6}$ GGT and ALP are liver enzymes, while serum bile acids concentration is a test of liver function. Serum bile acids concentrations greater than $50 \mathrm{umol} / \mathrm{L}$ have been associated with an increased risk of non-survival. ${ }^{5}$ Horses with subclinical PA toxicity may have increased activities of $\mathrm{GGT}^{10}$; therefore, it is recommended to serially monitor GGT in horses on the same property where there is a known case of PA intoxication.

Although reports exist of horses surviving PA intoxication, the prognosis is generally poor, especially when clinical signs are apparent. No specific treatment exists, but a horse's life may be prolonged by appropriate attention to supportive care and nutrition. The best prevention for this disease is to remove all PA-containing plants from the pasture and ensure hay sources are free from PA-containing plants.

Toxicity has also been reported from ingestion of Alsike clover (Trifolium hybridum) or red clover (Trifolium pratense). This legume grows in moist soils and has been cultivated as a forage source often alongside alfalfa. ${ }^{12}$ Horses can become exposed to Alsike clover through pasture grazing or consuming hay that contains the plant. The toxic principle is unknown ${ }^{12}$ but ingesting a diet that consists of $20 \%$ alsike clover for 2 weeks will induce signs of liver disease in horses. ${ }^{13}$ Clinical disease may manifest as acute or chronic hepatic dysfunction. Clinical signs of acute disease are those of hepatic encephalopathy, such as lethargy, depression, altered mental status, head pressing, and behavioral changes. Signs of chronic disease include ill thrift, anorexia, icterus, and lethargy. ${ }^{14}$ This disease is distinct from slaframine toxicosis (also known as black patch disease or "slobbers"), which is caused by ingestion of red clover infected with the fungus Rhizoctonia leguminicola and is characterized by hypersalivation without effects on the liver. It is also important to note that Alsike clover and red clover are a different genus from sweet clover (Melilotus sp). Moldy sweet clover consumption would result in clinical signs of coagulopathy (bleeding disorders).

Laboratory abnormalities associated with clover toxicity include high bilirubin levels, increases in liver enzymes, and increases in serum bile acids. Treatment is focused on supportive care and removal of the plant from the premises and hay. The prognosis is fair but depends on the degree of fibrosis in the liver, which is assessed with biopsy. Regeneration of the liver remains possible, and the liver may regain function as well.
Hepatic toxicity from ingestion of hay containing fall panicum (Panicum dichotomiflorum) has been documented in multiple horses in a boarding stable ${ }^{15}$ and has been reported in horses grazing the grass. ${ }^{16}$ Horses naturally intoxicated and two horses experimentally intoxicated developed signs of liver disease, including icterus, lethargy, anorexia, and weight loss, after the horses had been eating the contaminated hay for 2-3 weeks. The most notable laboratory abnormalities included marked increases in the activities of GGT, sorbital dehydrogenase (SDH), ALP, aspartate aminotransferase (AST), and mild to moderate increases in creatine kinase (CK). Marked increases in concentrations of total and unconjugated bilirubin and serum bile acids may also occur. The prognosis is fair to poor with 5 of 14 horses in one published report being euthanized due to clinical deterioration. ${ }^{15}$

\section{Diagnostic Testing}

Laboratory testing is required for diagnosis of liver disease. If your horse demonstrates any of these clinical signs, the horse should be evaluated by your veterinarian. Blood work, ultrasound examination, and liver biopsy provide the most comprehensive diagnostic utility. The enzymes specific for liver in the horse are GGT and SDH. Other, less specific enzymes that suggest liver disease when activities are increased include AST, lactate dehydrogenase (LDH), and ALP. Other laboratory abnormalities that are nonspecific may be seen on blood results as well.

Measurement of serum bile acids assesses liver function. Increases in bile acids may be caused by poor hepatic perfusion, or the inability of the liver cells to take up, conjugate, or excrete bile acids. Fasting is not required to be able to measure serum bile acids in the horse.

If horses have laboratory abnormalities that suggest a diagnosis of liver disease, a percutaneous liver biopsy is the sole method to determine a definitive diagnosis and prognosis for the life of the horse. ${ }^{19-21}$ Even with a biopsy, it is not possible to find a definitive cause of liver disease for all cases. A presumptive diagnosis may be made after considering if the horse had a history of exposure to toxic plants, along with the horse's clinical signs and laboratory abnormalities. It is recommended to perform the biopsy using ultrasound guidance. A transabdominal ultrasound enables evaluation of liver size and architecture, determination of the presence of masses or choleliths, and evaluation of blood vessels and the biliary tree. An appropriate site for biopsy may be chosen following a complete ultrasound examination. Evaluation of blood coagulation times (prothrombin time and activated partial thromboplastin time) 
should be performed prior to percutaneous biopsy. One study demonstrated that as many as $58 \%$ of horses with liver disease have abnormal coagulation times, but only $12.5 \%$ of horses had laboratory evidence of hemorrhage and no horses developed clinically significant hemorrhage. ${ }^{22}$ Liver biopsy results consistent with a poor prognosis include the degree of fibrosis (fibrous scar tissue) as well as other cell types that can indicate severe disease or cancer. ${ }^{23}$ Biopsy samples should be submitted for both microscopic examination and culture.

\section{Treatment}

Therapy for liver disease is largely supportive and may be directed at an underlying cause, if known. Other than removing the offending plants, a specific directed therapy for pasture-associated liver disease is not available. Treatment is unlikely to provide any significant benefit to the patient if the biopsy results reveal severe bridging fibrosis of the liver. Therapy may depend on the severity of clinical signs and/or evidence of hepatic failure. Intravenous fluids with supplemental 5\% dextrose and potassium may be beneficial for some cases and is indicated in hepatic encephalopathy (horses with neurologic signs). A low protein, high energy diet may be beneficial. Branched chain amino acid treatment may decrease the severity of neurologic signs. ${ }^{5}$ Additional therapies directed at hepatic encephalopathy are available but are beyond the scope of this publication.

Cholangiohepatitis, an infectious cause of liver disease, is typically included on the initial list of potential causes; therefore, broad spectrum antimicrobial therapy is warranted. The authors routinely utilize trimethoprim sulfamethoxazole as an initial choice if the patient is clinically stable and treatment is initiated prior to the results of liver biopsy. Penicillin/gentamicin, enrofloxacin, and metronidazole (in combination with the aforementioned choices) may also be utilized. Banamine ${ }^{\circledR}$ may be administered for its anti-inflammatory and analgesic effects. Pentoxifylline is a drug with anti-inflammatory properties and has been shown to reduce hepatic fibrosis in human patients. ${ }^{24}$

\section{Summary}

Pasture-associated liver disease can be commonly seen in equine practice. Knowledge of the plants that cause hepatic disease will promote early diagnosis and improve outcomes. Pyrrolizidine alkaloids, panicum grasses, and clover (alsike and red clover) are most commonly implicated. Liver biopsy may be able to differentiate toxic etiologies, but it is most helpful for determining the prognosis based on the presence or absence of fibrosis. Blood laboratory testing is critical for determining hepatic disease; and GGT, $\mathrm{SDH}$, and serum bile acids concentration are the most liver-specific.

\section{References}

1. M.H. Barton, "Disorders of the Liver," in Equine Internal Medicine 3 ed., ed.S.M. Reed, W.B. Bayly, and D.C. Sellon.

(St. Louis: Saunders Elsevier, 2010), 939-75.

2. T.J. Divers, "Liver Disease and Liver Failure in Horses," Proceedings 29 Convention of Am Assoc Equine Pract (1983): 213.

3. B.L. Stegelmeier, D.R. Gardner, L.F. James, et al., "Pyrrole Detection and the Pathologic Progression of Cynoglossum Officinale (Houndstongue) Poisoning in Horses," J Vet Diagn Invest 8 (1996): 81-90.

4. D. Bergero and J. Nery, "Hepatic Diseases in Horses," J Anim Physiol Anim Nutr (Berl) 92 (2008): 345-55.

5. V.E. Mendel, V.R. Witt, B.S. Gitchell, et al., "Pyrrolizidine Alkaloid-induced Liver Disease in Horses: An Early Diagnosis," Am J Vet Res 49 (1988): 572-8.

6. P. Lessard, W.D. Wilson, H.J. Olander, et al., "Clinicopathologic Study of Horses Surviving Pyrrolizidine Alkaloid (Senecio vulgaris) Toxicosis," Am J Vet Res 47 (1986): 1776-80.

7. A.P. Knight, C.V. Kimberling, F.R. Stermitz, et al., "Cynoglossum Officinale (Hound's-Tongue) - A Cause of Pyrrolizidine Alkaloid Poisoning in Horses," J Am Vet Med Assoc 15 (1984): 647-50.

8. J.H. Creeper, A.A. Mitchell, T.F. Jubb, et al., "Pyrrolizidine Alkaloid Poisoning of Horses Grazing a Native Heliotrope (Heliotropium ovalifolium)," Aust Vet J 77 (1999): 401-2.

9. C.J. Giles, "Outbreak of Ragwort (Senecio jacobea) Poisoning in Horses," Equine Vet J 15 (1983): 248-50.

10. J.M. Curran, R.J. Sutherland, and R.L. Peet, "A Screening Test for Subclinical Liver Disease in Horses Affected by Pyrrolizidine Alkaloid Toxicosis," Aust Vet J 74 (1996): 236-40.

11. T. Chen, N. Mei, and P.P. Fu, "Genotoxicity of Pyrrolizidine Alkaloids," J Appl Toxicol 30 (2010): 183-96. 
12. P.N. Nation, "Hepatic Disease in Alberta Horses: A Retrospective Study of Alsike Clover Poisoning (19731988)," Can Vet J 32 (1991): 602-7.

13. P. Talcott, "Alsike Clover and Red Clover Poisonings in Horses," Proceedings 18 Am Coll Vet Intern Med Forum (2000): 161.

14. P.N. Nation, "Alsike Clover Poisoning: A Review," Can Vet J 30 (1989):410-5.

15. A.L. Johnson, T.J. Divers, M.L. Freckleton, et al., "Fall Panicum (Panicum dichotomiflorum) Hepatotoxicosis in Horses and Sheep," J Vet Intern Med 20 (2006): 1414-21.

16. J.L. Cornick, G.K. Carter, and C.H. Bridges, "Kleingrassassociated Hepatotoxicosis in Horses." J Am Vet Med Assoc 193 (1988): 932-5.

17. T.J. Divers, "Biochemical Diagnosis of Hepatic Disease and Dysfunction in the Horse," Vet Clin North Am Equine Pract 15 (1993): 15.

18. K. Sherman, R. Wells, and M. Mattiacci, "Lability of Sorbitol Dehydrogenase in Refrigerated and Frozen Horse Serum," J Equine Vet Sci 11 (1991): 176.

19. A.E. Durham, J.R. Newton, K.C. Smith, et al., "Retrospective Analysis of Historical, Clinical, Ultrasonographic, Serum Biochemical and Haematological Data in Prognostic Evaluation of Equine Liver Disease," Equine Vet J 35 (2003): 542-7.

20. A.E. Durham, K.C. Smith, and J.R. Newton, "An Evaluation of Diagnostic Data in Comparison to the Results of Liver Biopsies in Mature Horses." Equine Vet J 35 (2003): 554-9.

21. M.R.W. Smith, K.B. Stevens, A.E. Durham, et al., "Equine Hepatic Disease: The Effect of Patient- and CaseSpecific Variables on Risk and Prognosis," Equine Vet J 35 (2003): 549-52.

22. I.C. Johns and R.W. Sweeney, "Coagulation Abnormalities and Complications after Percutaneous Liver Biopsy in Horses," J Vet Intern Med 22 (2008): 185-9.

23. A.E. Durham, K.C. Smith, J.R. Newton, et al., "Development and Application of a Scoring System for Prognostic Evaluation of Equine Liver Biopsies," Equine Vet J 35 (2003): 534-40.
24. C. Windmeier and A.M. Gressner, "Pharmacological Aspects of Pentoxifylline with Emphasis on Its Inhibitory Actions on Hepatic Fibrogenesis," Gen Pharmacol 29 (1997): 181-96. 